\title{
In Vivo Regulation of Secretion of Bronchiolar Clara Cells in Rats
}

\author{
Gloria D. Massaro, Marguerite Paris, and Lyn Aung Thet, Pulmonary Division, \\ Oak Asthma Research and Treatment Facility, University of Miami School of \\ Medicine, Miami, Florida 33152, and Veterans Administration Hospital, \\ Miami, Florida 33101
}

\begin{abstract}
A B S T R A C T We used ultrastructural morphometric methods to study the in vivo regulation of secretion in bronchiolar Clara cells of rats. The Clara cells studied were located in airways with an internal diameter of $0.21 \pm 0.06 \mathrm{~mm}($ mean $\pm \mathrm{SD})$ at a transpulmonary pressure of $20 \mathrm{~cm} \mathrm{H}_{2} \mathrm{O}$. We found that pilocarpine caused a $50 \%$ decrease in the volume density of secretory granules of Clara cells in $60 \mathrm{~min}$ and that atropine blocked this effect. Isoproterenol produced a similar fall in volume density and this was blocked by propranolol. Propranolol also blocked the effect of pilocarpine. The fall in volume density of the secretory granules produced by pilocarpine and by isoproterenol occurred without any change in the surface-to-volume ratio of the granules. This indicates the change in volume density reflected a decrease in number rather than in size of the secretory granules. The observation that propranolol blocks the secretory response to pilocarpine as well as the response to isoproterenol suggests a dual in series cholinergic adrenergic regulation of secretion in bronchiolar Clara cells in rats.
\end{abstract}

\section{INTRODUCTION}

Clara cells are epithelial cells located mainly within distal conducting airways (1-3). Although they are thought to secrete components of the extracellular lining layer of these airways (1), little is known about the nature of the secretory products, about the function of these products, or about the neurohumoral regulation of secretion in these cells. This lack of information may be particularly unfortunate because Clara cells are located mainly in small airways which are thought to be the sites of initial damage and dysfunc-

This work was presented in part at the 70th Annual Meeting of the American Society for Clinical Investigation, San Francisco, Calif., 28 April-1 May 1978.

Received for publication 11 September 1978 and in revised form 20 October 1978. tion in the most prevalent forms of chronic pulmonary disease in humans.

Study of the Clara cell has been seriously hampered because they have not been successfully isolated by cell separation or tissue culture techniques, and because their secretory products have not been identified and characterized. These considerations led to this study in which we have used ultrastructural morphometric methods to examine aspects of the in vivo neurohumoral regulation of secretion by Clara cells of rats.

\section{METHODS}

Animals. We used male Long Evans rats (Charles River Breeding Laboratories, Inc., Wilmington, Mass.). These were maintained by us on a 12-h light dark cycle and allowed food (Wayne Lab-Blox, Allied Mills, Inc., Chicago, Ill.) and water ad libitum until sacrificed.

Experimental procedures. The secretory agonists and antagonists were injected intraperitoneally into unanesthetized rats. We used pilocarpine ( $150 \mathrm{mg} / \mathrm{kg}$ body $\mathrm{wt}$ ), atropine (14 mg/kg), isoproterenol (10 mg/kg), and propranolol $(2.0 \mathrm{mg} /$ $\mathrm{kg}$ ). These were given in $0.15 \mathrm{M} \mathrm{NaCl}$; control rats received an equal volume of $\mathrm{NaCl}$ alone.

At specified times the rats were anesthetized by the intraperitoneal injection of pentobarbital sodium $(30 \mathrm{mg} / \mathrm{kg})$. The trachea was cannulated through a midline cervical incision while the animals were still breathing. A bilateral pneumothorax was produced by puncturing the diaphragm from its abdominal surface. We then infused $2.5 \%$ cold glutaraldehyde

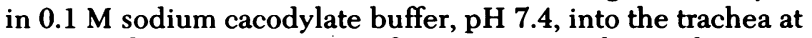
a transpulmonary pressure of $20 \mathrm{~cm} \mathrm{H}_{2} \mathrm{O}$. The trachea was ligated, the lungs removed from the thoracic cavity, and fixation was continued by placing the lungs in fixative for $2 \mathrm{~h}$ at $0-4^{\circ} \mathrm{C}$.

Preparation of tissue. A stratified sample of tissue was obtained by removing one piece from five different areas of lung: left upper, middle, and lower lung and right upper and lower lung. These were placed in fresh cacodylate buffer. A dissecting microscope was used to identify areas containing bronchioles; blocks cut from these areas were washed three times in cacodylate buffer, kept at $4^{\circ} \mathrm{C}$ overnight, and then postfixed in $2 \%$ osmium tetroxide in $0.1 \mathrm{M}$ sodium cacodylate buffer, $\mathrm{pH}$ 7.4. The tissue was then dehydrated and embedded as described in detail (4).

$1-\mu \mathrm{m}$ thick sections of the bronchioles were cut and stained 
with toluidine blue. These conducting airways were measured with an eyepiece reticule. They had an internal diameter of $0.21 \pm 0.06 \mathrm{~mm}($ mean $\pm \mathrm{SD})$ with a range of $0.11-0.39 \mathrm{~mm}$.

Tissue blocks were sectioned on a Porter-Blum ultramicrotome (DuPont Instruments, Sorvall Operations, Newton, Conn.) with a diamond knife. Sections with a silver interference color were picked up on 200 mesh copper grids. These were stained with uranyl magnesium acetate and lead citrate (5) and examined with a Philips 300 electron microscope (Philips Electron Instruments, Inc., Mahwah, N. J.).

Sampling procedures. The primary sample consisted of some 50 tissue cubes ( 10 from each of 5 stratified areas). From the 5 sets of 10 numbered cubes, one was chosen, using a random number table, from each set to represent the secondary sample. Each of these blocks was sectioned at $1 \mu \mathrm{m}$ for light microscopy and at 600-900 $\AA$ for electron microscopic examination. Nine electron micrographs of Clara cells were taken from each block. Thus, from each rat we used five blocks and made $\mathbf{4 5}$ micrographs. The micrographs of Clara cells were taken randomly and enlarged to a final magnification of 15,750 .

Stereological procedures. Morphometric analysis was

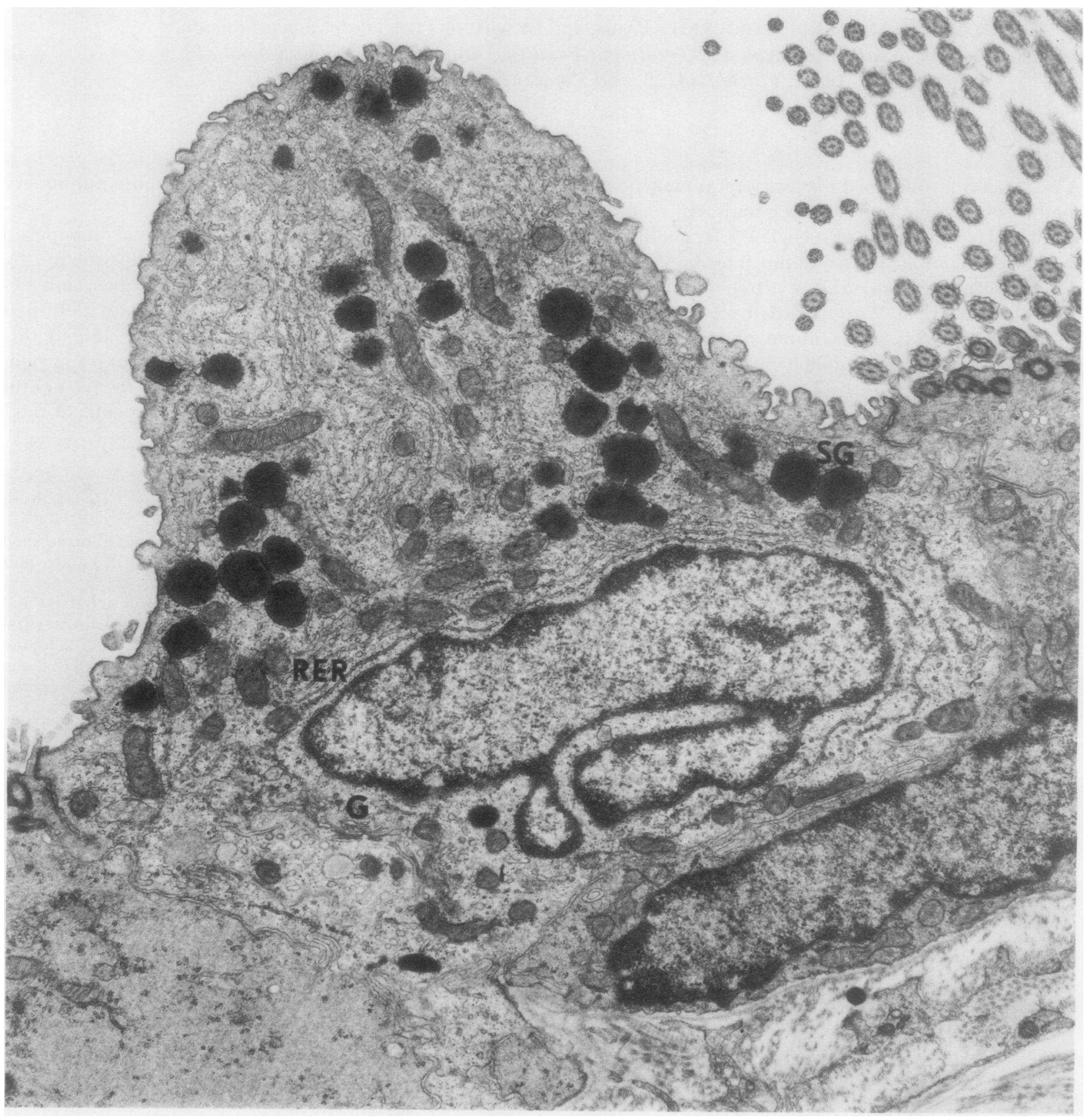

FIGURE 1 Electron micrograph of a Clara cell. The rough endoplasmic reticulum (RER), Golgi apparatus $(\mathrm{G})$ and secretory granules $(\mathrm{SG})$ may be seen. 
performed using the methods of Weibel et al. $(6,7)$. A multipurpose test system (6) $17.6 \times 17.6 \mathrm{~cm}$ having 168 test points $1.5 \mathrm{~cm}$ apart was used to estimate the volume density and the surface-to-volume ratio of secretory granules. For calculation of volume density we counted enough test points in each animal to attain a relative error in each instance of $<5 \%$ (6). The volume density and surface-to-volume ratio of the secretory granules were calculated by standard methods (6).

Identification of Clara cells. In the conducting airways that had been measured by light microscopy, Clara cells were identified by electron microscopy as nonciliated cells abutting on, and frequently protruding into, the airway lumen. Most had one or more secretory granules and all had microvilli. An example of what was considered to be a Clara cell is shown in Fig. 1.

Statistical analysis. For each of the parameters measured or calculated from these measurements, the values for individual animal were averaged per experimental group and the standard error of the group mean calculated. The significance of differences between groups was calculated by an unpaired $t$ test analysis (8).

\section{RESULTS}

Effects of pilocarpine and atropine. The timecourse of the effect of pilocarpine on the volume density of secretory granules was examined. We found a fall of $\cong 25 \%$ in the volume density of the secretory granules within $30 \mathrm{~min}$ and $\cong 50 \%$ within $60 \mathrm{~min}$ after administering pilocarpine (Fig. 2). Within $2 \mathrm{~h}$ after giving pilocarpine, the volume density of the secretory granules had returned to control levels. Atropine blocked the fall in the volume density of the secretory granules brought about by pilocarpine (Fig. 3).

We also examined the effect of pilocarpine and atropine on the volume fraction of the secretory granules by relating the number of test probe points falling on the secretory granules to the fixed number of points on the test system. This showed that the volume

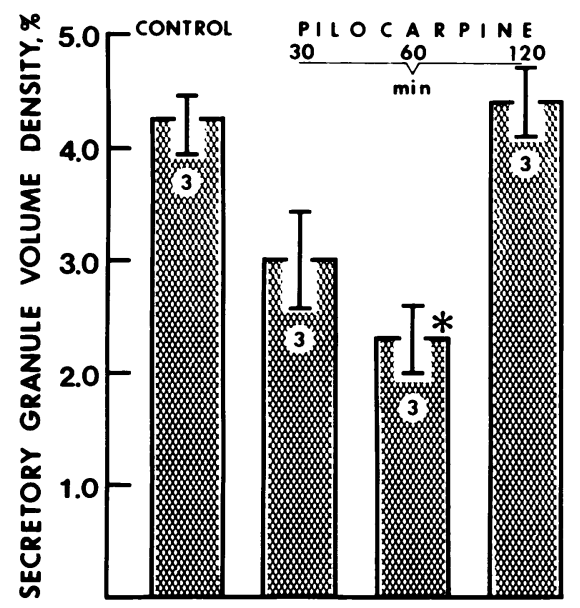

Figure 2 Time-course of the effect of pilocarpine. Mean $\pm \mathrm{SE}$ are given and the numbers within the blocks indicate the number of animals. $\left(^{*}\right)$ Indicates $P<0.01$ compared to the control.

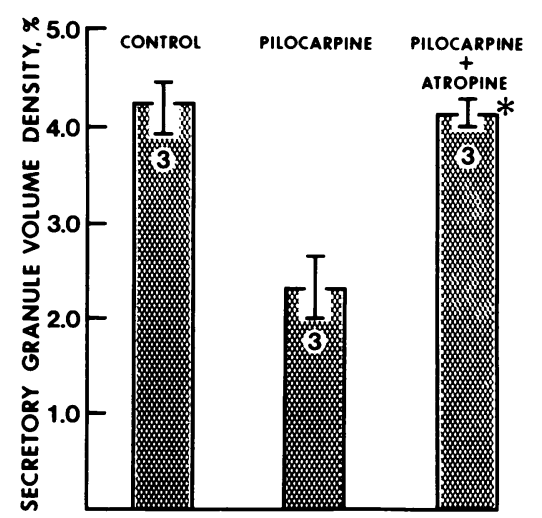

Figure 3 Effect of atropine. Mean $\pm \mathrm{SE}$ are given and the numbers within the blocks indicate the number of animals. $\left(^{*}\right)$ Indicates $P<0.01$ compared to the pilocarpine alone. All animals sacrificed $1 \mathrm{~h}$ after injection.

density of the secretory granules determined in this manner also fell after the administration of pilocarpine, and that this fall too was blocked by atropine (Table I). The surface-to-volume ratio of the secretory granules was not changed by pilocarpine or by pilocarpine plus atropine (Table II).

Effects of isoproterenol. Isoproterenol produced a fall in the volume density of Clara cell secretory granules equal to that produced by pilocarpine, and this effect was blocked by propranolol (Fig. 4). The secretory granule volume density relative to the fixed number of points of the test system also fell after isoproterenol; propranolol blocked this effect (Table III). These two agents did not alter the surface-to-volume ratio of the secretory granules (Table IV).

Effect of propranolol on the response to pilocarpine. The secretory response to both pilocarpine and isoproterenol suggests possible dual cholinergic-adrenergic control of secretion in the Clara cells. This dual control might be in series or in parallel. We therefore examined the effect of propranolol on the secretory response to pilocarpine; propranolol completely blocked the fall in volume density of the secretory

\section{TABLE I}

Effect of Pilocarpine and Atropine on the Volume Density of Clara Cell Secretory Granules Relative to the Test System

\begin{tabular}{lcl}
\hline \multicolumn{1}{c}{ Condition } & Volume density & $P$ \\
\hline & $\%$ & \\
Control & $1.73 \pm 0.13$ & \\
Pilocarpine & $1.00 \pm 0.13$ & $<0.025$ \\
Pilocarpine + atropine & $1.62 \pm 0.27$ & $>0.4$ \\
\hline
\end{tabular}

The animals were killed $1 \mathrm{~h}$ after injecting the diluent or the pharmacological agent. Values are mean $\pm S E, n=3$ in each instance. 
TABLE II

Effect of Pilocarpine and Atropine on the Surface-to-Volume Ratio of Clara Cell Secretory Granules

\begin{tabular}{lcc}
\hline \multicolumn{1}{c}{ Condition } & Surface-to-volume ratio & $P$ \\
\hline & $\mu \mathrm{m}^{2} / \mu \mathrm{m}^{3}$ & \\
Control & $8.37 \pm 0.53$ & \\
Pilocarpine & $9.29 \pm 0.87$ & $>0.2$ \\
Pilocarpine + atropine & $7.24 \pm 0.57$ & $>0.2$
\end{tabular}

The animals were killed $1 \mathrm{~h}$ after injecting the diluent or the pharmacological agents. Values are mean $\pm \mathrm{SE}, n=3$ in each instance.

granules produced by pilocarpine, i.e., the volume density of secretory granules after pilocarpine is $2.31 \pm 0.32$ (Fig. 2), and after pilocarpine plus propranolol the volume density is $5.35 \pm 0.28$ (mean $\pm \mathrm{SE}$, $n=3, P<0.005$ ). The secretory granule volume fraction relative to the number of fixed number of points on the test system is $1.00 \pm 0.13$ (Table I) for pilocarpine injected rats; for rats given pilocarpine plus propranolol the value is $2.01 \pm 0.13$ (mean $\pm \mathrm{SE}, n=3$, $P<0.005)$.

\section{DISCUSSION}

Nonciliated epithelial cells (Clara cells) in small conducting airways have been recognized for many years (1-3). Recently, Reid (3) has divided airway secretory epithelial cells into three types - serous, Clara, and goblet. Jeffrey and Reid (9) reported that serous cells are present in large airways and that the Clara cell, although mainly in small airways $<0.4 \mathrm{~mm}$ in diameter, can, at times be seen in much larger airways. Epithelial serous cells are generally flat, whereas Clara cells usually protrude into the airway lumen. In this study

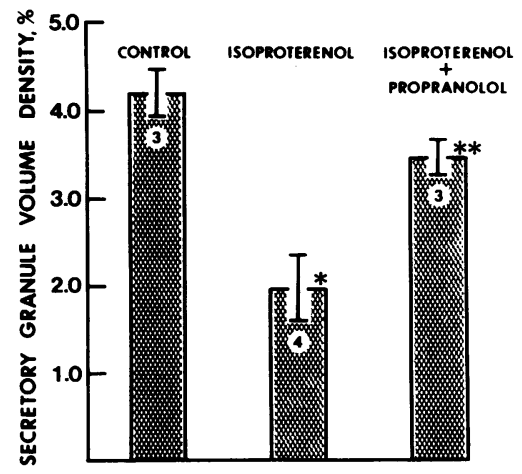

FIGURE 4 Effect of isoproterenol and propranolol. Mean \pm SE are given and the numbers within the blocks indicate the number of animals. $\left(^{*}\right)$ Indicates $P<0.01$ compared to control and $\left({ }^{* *}\right)$ indicates $P<0.025$ compared to isoproterenol alone. All animals sacrificed $1 \mathrm{~h}$ after injection.
TABLE III

Effect of Isoproterenol on the Volume Density of Clara Cell Secretory Granules Relative to the Test System

\begin{tabular}{lcc}
\hline \multicolumn{1}{c}{ Condition } & Volume density & $P$ \\
\hline & $\%$ & \\
& & \\
Control (3) & $1.73 \pm 0.13$ & \\
Isoproterenol (4) & $0.77 \pm 0.16$ & 0.01 \\
Isoproterenol + propranolol (3) & $1.48 \pm 0.21$ & $>0.1$ \\
& & $<0.05$ \\
\end{tabular}

The animals were killed $1 \mathrm{~h}$ after injecting the diluent or the pharmacological agents. Values are mean \pm SE. Figures in parentheses indicate number of animals. $P$ values are compared to control except 0.05 , which is relative to isoproterenoltreated rats.

we have limited our examination to Clara cells located in airways with an internal diameter $<0.4 \mathrm{~mm}$ at a transpulmonary pressure of $20 \mathrm{~cm} \mathrm{H}_{2} \mathrm{O}$. This limitation was applied to more sharply define the location of the cells compared to the less clearly defined "small airway," and because of the possibility that cells at different levels of the conducting airways may be under different neurohumoral regulation.

We have used a morphometric ultrastructural evaluation of inclusion bodies in Clara cells to assess secretion. The choice of this technique was dictated by the absence of methods to isolate these cells in pure form and by the lack of characterized secretory products. Our analysis rests on the assumption that these cells are indeed secretory cells and that changes in the volume density of these inclusions are because of secretion. The former assumption seems relatively secure because of the vast literature describing the ultrastructural characteristics of cells which make and store proteins destined to be secreted $(10,11)$. These reports

TABLE IV

Effect of Isoproterenol and Propranolol on the Surface-to-Volume Ratio of Clara Cell Secretory Granules

\begin{tabular}{lcc}
\hline \multicolumn{1}{c}{ Condition } & Surface-to-volume ratio & $P$ \\
\hline & $\mu \mathrm{m}^{2} / \mu \mathrm{m}^{3}$ & \\
Control (3) & $8.37 \pm 0.53$ & \\
Isoproterenol (4) & $7.98 \pm 0.48$ & $>0.5$ \\
Isoproterenol (3) + propranolol & $7.36 \pm 0.28$ & $>0.1$ \\
& & $>0.5$
\end{tabular}

The animals were killed $1 \mathrm{~h}$ after injecting the diluent or the pharmacological agents. Mean $\pm \mathrm{SE}$ are given. Figures in parentheses indicate number of animals. $P$ values are compared to control except 0.5 , which is relative to isoproterenol treated rats. 
have shown that secretory cells, irrespective of the organ or tissue of origin, generally have an ample rough endoplasmic reticulum, a well-developed Golgi apparatus, and inclusion bodies that serve as storage granules. The Clara cell clearly has these ultrastructural features (Fig. 1).

We have considered the following possibilities in interpreting the changes in volume density of the secretory granules in response to pilocarpine and to isoproterenol. First, changes in the volume fraction relative to the cell could reflect differences in the cell volume, rather than a fall in the volume of secretory granules. We think that our studies relating the volume fraction of the secretory granules to the fixed number of points on the test system excludes changes in cell volume as the cause of the decrease in the volume density of the secretory granules.

A second possibility considered is that changes in the volume density of secretory granules could represent decreased synthesis of secretory products in the face of an unchanged rate of secretion, rather than an increased rate of secretion. We have not excluded this possibility and, in fact, cannot with the presently available technology. However, to our knowledge, there are no examples in the literature to support the notion that such a substantial reduction in intracellular secretory material after the administration of secretogogues is a result of alterations in synthesis rather than increased secretion.

Finally, considering the effect of pilocarpine and of isoproterenol on the volume density and surface-tovolume ratio sheds some light on the cellular events that follow the administration of these agents. A decrease in the size of an organelle will increase the surface-to-volume ratio. Our failure to find a change in this ratio after the administration of pilocarpine or of isoproterenol, coupled with the fall in volume fraction, indicates that the latter is a result of a decrease in the number of secretory granules, rather than a change in their size. Although this does not argue against a decrease in synthesis it is what one would expect in a secretory process.

Our studies showed that pilocarpine lowered the volume density of secretory granules and that this could be blocked by atropine. This is consistent with cholinergic-mediated secretion where pilocarpine mimicked the effect of postganglionic parasympathetic stimulation of Clara cells. The fall in the volume density of secretory granules after the administration of isoproterenol and the blocking of this effect by propranolol is consistent with $\beta$-adrenergic involvement in secretion by Clara cells of the rat. It is theoretically possible that the cholinergic and adrenergic effect are mediated in parallel or in series. The blockade of the secretory effect of pilocarpine by propranolol, a $\beta$ - adrenergic blocker, suggests, but does not prove (12) an in series cholinergic adrenergic regulation of secretion in the Clara cell.

Burn and Rand (13) first proposed a cholinergic component in adrenergic transmission to explain the finding that in several organs acetylcholine exerts action similar to that of sympathetic stimulation. This action was nicotinic rather than muscarinic in nature because it may be seen in the presence of atropine and is also produced by nicotine. Subsequently, Lloyd (14) reported studies on sweat glands in which he found evidence for dual control of sweating by cholinergic and adrenergic agents; the effect of both could be completely eliminated by adrenergic blockade, and the effect of cholinergic agents could be blocked by atropine. This led Lloyd (14) to conclude that the duality of cholinergic and adrenergic regulation of secretion in the sweat gland was mediated in series with acetylcholine acting prejunctionally and noradrenaline postjunctionally. Our findings in the Clara cell are similar to those of Lloyd for sweat glands and may be subjected to the same interpretation, but with the same limitations (12).

Because our studies were performed in vivo, the anatomical site of any proposed in series cholinergic adrenergic regulation of secretion remains unclear. It is possible that pilocarpine stimulated the adrenal gland to release sympathomimetic agents (15) and that the latter acted upon the Clara cell. A second consideration is that the cholinergic action might be on the central nervous system whose stimulation might evoke a secondary adrenergic stimulation (16). Finally, both cholinergic and adrenergic mechanisms, in series or not, may be mediated by intrapulmonary nerves.

One additional area requires comment. Yoneda (17) recently reported that pilocarpine increases the volume density of secretory granules in the Clara cells of rats. This finding is clearly at odds with the effect of pilocarpine we are reporting, and we cannot explain this difference. Both studies used the same dose of pilocarpine, although administered by different routes, and the same species but different strains. However, Yoneda (17) fasted the rats that received pilocarpine and his control rats were either fasted or fed; all our rats were fed ad libitum. We are unaware of any studies showing an increase in secretory granules after administration of a cholinergic agent that occurs so rapidly, i.e., within $30 \mathrm{~min}$ and without an initial release of secretory product.

\section{ACKNOWLEDGMENTS}

This work was supported in part by National Heart and Lung Institute grants HL-22333, HL-00374, HL-20366, Veterans Administration research funds, and Veterans Administration Research Electron Microscopy Laboratory. 


\section{REFERENCES}

1. Kuhn, C. 1976. The cells of the lungs and their organelles. In The Biochemical Basis of Pulmonary Function, R. G. Crystal, editor. Marcel Dekker, Inc., New York, 3-48.

2. Weibel, E. R., P. Gehr, D. Haies, J. Gil, and M. Bachofen. 1976. In Lung Cells in Disease. A. Bouhuys, editor. Elsevier North-Holland, Inc., New York. 3-16.

3. Reid, L. M. 1977. Secretory cells. Fed. Proc. 36: 27032707.

4. Massaro, G. D., and D. Massaro. 1972. Granular pneumocytes: electron microscopic radioautographic evidence of intracellular protein transport. Am. Rev. Respir. Dis. 105: 927-931.

5. Massaro, D., K. Kelleher, G. Massaro, and H. Yeager. 1970. Alveolar macrophages: depression of protein synthesis during phagocytosis. Am. J. Physiol. 218: 1533-1539.

6. Weibel, E. R. 1973. Stereological techniques for electron microscopic morphometry. In Principles and Techniques of Electron Microscopy. M. A. Hyatt, editor. Van Nostrand Reinhold Company. New York. 3: 237-296.

7. Weibel, E. R., G. S. Kistler, and W. R. Scherle. 1966. Practical stereological methods for morphometric cytology. J. Cell Biol. 30: 23-88.

8. Snedecor, G. W., and W. G. Cochran. 1967. Statistical
Methods. Iowa State University Press, Ames, Iowa. 6th edition. 91-119.

9. Jeffery, P. K. and L. Reid. 1975. New observations of rat airway epithelium: a quantitative and electron microscopic study. J. Anat. 120: 295-320.

10. Schramm, M. 1967. Secretion of enzymes and other macromolecules. Ann. Rev. Biochem. 36: 307-320.

11. Palade, G. 1975. Intracellular aspects of the process of protein synthesis. Science (Wash. D. C.). 189: 347-358.

12. Ferry, C. B. 1966. Cholinergic link hypotheses in adrenergic neuroeffector transmission. Physiol. Rev. 46: 420456.

13. Burn, J. H., and M. J. Rand. 1959. Sympathetic postganglionic mechanism. Nature (Lond.). 184: 163-165.

14. Lloyd, D. P. C. 1965. Cholinergy and adrenergy in the neural control of sweat glands. In Studies in Physiology. D. R. Curtis and A. K. McIntyre, editors. Springer-Verlag New York, Inc., New York, 169-178.

15. Feldberg, W., B. Minz, and H. Tsudzimura. 1934. The mechanism of the nervous discharge of adrenaline. $J$. Physiol. (Lond.). 81: 286-304.

16. Light, R. U., C. C. Bishop, and L. G. Kendall. 1933. The response of the rabbit to pilocarpine administration into the cerebrospinal fluid. J. Pharmacol. Exp. Ther. 47: 37-45.

17. Yoneda, K. 1977. Pilocarpine stimulation of the bronchiolar Clara cell secretion. Lab. Invest. 37: 477-452. 